\section{Costs of care provided in a university hospital for children exposed to or infected with the HIV/AIDS}

\author{
Custos da atenção à saúde das crianças expostas \\ ou infectadas por HIV/AIDS atendidas em um \\ hospital universitário
}

\author{
${ }^{1}$ Faculdade de Medicina, \\ Universidade de São Paulo, \\ São Paulo, Brasil. \\ 2 Faculdade de Saúde \\ Pública, Universidade de \\ São Paulo, São Paulo, Brasil. \\ 3 Centro de Referência e \\ Treinamento de DST/AIDS \\ Secretaria de Estado da \\ Saúde, São Paulo, Brasil. \\ Correspondence \\ H. H. S. Marques \\ Hospital das Clínicas, \\ Faculdade de Medicina, \\ Universidade de São Paulo. \\ Av. Dr. Enéas de Carvalho \\ Aguiar 647, São Paulo, SP \\ 05403-900, Brasil. \\ heloisahsm@icr.hcnet.usp.br
}

\begin{abstract}
The objective of this study was to estimate and analyze the costs of treating children with HIVIAIDS at a university hospital in São Paulo, Brazil. The study collected and analyzed data from 291 medical records of children treated at the hospital as of March 2002. The costs of treatment were estimated for each category of patient (exposed and infected) and severity, based on the quantity of inputs and procedures used in treating each child, based on the cost accounting system used at the hospital. The total cost of treatment for children exposed to the HIV was $R \$ 956.41$ and for those infected with HIV $R \$ 8,092.71$ per year. The mean cost of ambulatory care was $R \$ 6,047.28$ for children with severe conditions, $R \$ 3,714.45$ for those with light/moderate conditions, and $R \$ 948.63$ for the exposed. Hospitalized children had annual costs of $R \$$ $19,353.34, R \$ 18,823.16$, and $R \$ 871.03$, respectively. The medication was a major factor in the cost of treatment. Our estimates are comparable to the findings from other studies, but lower than corresponding findings from the international literature.
\end{abstract}

HIV; Acquired Immunodeficiency Syndrome; Health Care Costs; Child Care
Heloisa Helena de Sousa Marques 1

Bernard François Couttolenc ${ }^{2}$

Maria do Rosário Dias de Oliveira Latorre 2

Maria Zilda de Aquino 1

Maria Ignez Garcia Aveiro 1

Ana Maria Aratangy Pluciennik 3

\section{Introduction}

In Brazil, an increase in the transmission of HIV through unprotected heterosexual intercourse has led to an increase in the number of women infected by the virus. As the majority of these women are fertile, many become pregnant, resulting in an increase in the number of children exposed to the infection. Children exposed to HIV may or may not acquire the infection, and must be followed up, as well as those children diagnosed as infected, in accordance with the recommendation established in the Guia de Tratamento Clínico da Infecção pelo HIV em Crianças (Guidelines for Clinical Treatment of the HIV Infection in Children) issued by the Ministry of Health 1.

Brazil has been praised globally for its actions in the fight against HIV/AIDS, particularly in regard to supplying free and universal treatment to all those infected or ill 2,3. Despite the magnitude of expenditures involved in healthcare for these clients, there have been few studies done about treatment costs carried out in the country. A better comprehension about the costs of healthcare is important, as it permits working out more realistic public health budgeting, enabling the identification of unnecessary or excessive costs, the review and reformulation of public policy, or treatment strategies, or even the adoption of measures to ensure the sustainability of the program, or treatment 
under analysis. In addition, this information is indispensable for the definition of realistic payment values for the Brazilian Unified National Health System (SUS), the main funding source for the management and care of people living with HIV/AIDS in the country for both public and private health providers.

The few studies about HIV/AIDS treatment costs that exist in Brazil have evaluated the costs of adult treatment, and up to this time there had been no parameters established for costs of treatment for children 4,5,6. The main studies that estimate treatment costs for HIV infected/exposed children have been carried out in developed countries, and involve, in general, a small number of patients $7,8,9$. This study aims to estimate and analyze the healthcare costs for children exposed to HIV through their mothers and for children infected or ill with AIDS followed in a reference hospital.

\section{Methodology}

\section{Population of the study}

All the medical files of children exposed or infected that were being followed up at the Instituto da Criança, Hospital das Clínicas, Faculdade de Medicina, Universidade de São Paulo [Child Health Institute, University Hospital, School of Medicine, University of São Paulo], a total of 291 records, were studied and analyzed as of March, 2002. At the Instituto da Criança, children are followed up by three different units - ambulatory (outpatients), day-hospital, and infirmary (inpatients) - in function of the severity of their medical conditions and other characteristics; the three alternatives are considered separately in this study. Based on the medical files, information was collected about all treatments and procedures carried out, as well as medications and supplies utilized, from January to June, 2001. The project was approved by the local Institutional Review Board - CAPPesq n. 661/01 on September 27, 2001. It was financed by the AIDSII/UNESCO agreement, project n. CFA 709/01, Brazilian National STD/AIDS Program (PN DST/AIDS), Brazilian Ministry of Health.

\section{General methodology}

Two factors contributed directly in determining the annual costs of treatment: the quantity of visits and procedures carried out and the supplies consumed by the patients during the period, and the unitary value of each procedure and supply 10 .
In function of this, a specific methodology was developed for estimating the costs of treatment, starting with individual medical records. This methodology consisted of three stages: (1) collection of data on procedures and supply utilization for each patient using a specially designed instrument; (2) tabulation and analysis of data and calculation of the average utilization of supplies and procedures for each patient category, employing Microsoft Excel spreadsheets (Microsoft Corp., U.S.A.); (3) estimation of average cost of treatment per category, based on the utilization of supplies/procedures and the cost of supplies used. Patients were classified into three categories based on their serological status and the severity of their medical condition: HIV exposed, mild/moderate condition, and severe condition.

\section{Data collection}

Three instruments were elaborated for data collection. The first was utilized for collecting information about demographic characteristics (sex, birth date), the child's clinical situation (date of registration at the facility), date of HIV diagnosis, date of death, transmission mode, CDC (Centers for Disease Control and Prevention) classification of their clinical status, current CD4+T cell count and viral load), and current therapeutic regimen (antiretroviral drugs - ARV, prophylaxis according to PACTG-076, prophylaxis against PJP (Pneumocystis jirovecii pneumonia, formerly $P$. carinii pneumonia) and monthly use of IVIG (intravenous gamma globulin). The second one was elaborated and adapted, starting with a study carried out previously to estimate the cost of treating adults living with HIV/AIDS 5. The spreadsheets from this second instrument were utilized to collect information about the type and quantity of procedures and treatments carried out on children participating in the study. Each alternative extant at the Instituto da Criança (ambulatory, day-hospital, and hospitalization) was the object of a specific spreadsheet for collection of information about the number of diagnostic exams carried out (hematology, biochemical, immunological, molecular biology, microbiology, other exams/special exams, imaging diagnostics) and procedures (medical consultations, other consultation, therapeutic procedures, nutrition/ medication, and surgery), hospital stays, diets, and vaccines.

For the last ones, and in function of the high costs involved, a specific instrument was developed for collecting information about the consumption of medications. Information was collected about utilization of ARV, antivirals, intra- 
venous gamma globulin, prophylaxis against PJC and/or other prophylaxis, tuberculosis management and care, vitamins and minerals, antibiotics, hemoderivates, antineoplastics, fungicides, sera, and other medications.

Average time for data collection for each patient was two hours for those hospitalized, and between 20 and 30 minutes for those who were outpatients or attending the day-hospital.

The data collected about supplies and consumed services, recorded on a Microsoft spreadsheet, were utilized for estimating costs and were entered into the statistical package SPSS for Windows version 10.0 (SPSS Inc., Chicago U.S.A.), to carry out additional descriptive analyses.

\section{Estimation of costs}

The cost of caring for children is based on the average utilization of medications, other supplies, and procedures by patient category (infected subdivided into light/moderate, severe, and exposed). Average cost for each patient category was estimated by multiplying the quantity of supplies and procedures utilized by their unitary cost. The cost was calculated by groups of supplies and services, according to standard hospital costs, and later aggregated to obtain total cost. The groups of supplies and procedures considered were: daily hospital rates, diagnostic exams, medical and other procedures, and medications.

Unitary cost was obtained from two sources: (i) for daily hospital rates, exams and hospital procedures, the average cost utilized was obtained through the cost monitoring system implemented at Instituto da Criança, which is based on the methodology of cost absorption; (ii) for medications, which constitute an important part of total cost, the price of acquisition by the Instituto da Criança was employed. Cost absorption methodology is used by taking the direct costs (those associated directly with the activity), and indirect ones (those associated with infrastructure, general support services, and administration) from each cost center, and then distributing the costs of support and administration to the cost centers responsible for the final products, such as ambulatory, hospital wards, etc. (this procedure is called prorating). Some exams and services, such as microbiology and special exams, that could not be done at the Instituto da Criança, but only at the central laboratory of the Hospital das Clínicas (which does not have a cost control center) had their unit cost estimated by using the table of market prices (as provided by the standard service remuneration spreadsheet, issued by the Brazilian Medical Association 11).
It is important to emphasize that the cost of each treatment alternative was centered on the main activity or modality of care - ambulatory medical consultation, day-hospital consultation, and hospitalization - but includes all the procedures associated with the main care modality: diagnostic exams, consultations and procedures done by non-medical professionals, etc. Or, in other words, the cost estimate for each modality encompasses the group of activities carried out for treating the patient in that modality.

Costs are presented in Reais ( $\mathrm{R} \$ 1.00$ roughly corresponds to US\$ 0.50, as of September 2007).

\section{Results}

The first results to be presented are those relative to the profile of the patients that were treated, followed by the unit costs per procedure, the costs per mode of treatment and category of patient, and, finally, the consolidated annual treatment cost.

\section{A brief description of patient profiles}

Of the 291 children whose medical files were analyzed, 112 were exposed to HIV (39\%), and 179 were infected, of which 73 ( $25 \%$ of total) were classified as being in the "light or moderate condition" category, according to the clinical-immunological guidelines for HIV infected children defined by the CDC 12 , and 106 (36\% of total) were classified as being in the grave category. The majority had been diagnosed at 12 months or older $(67 \%)$, and, during the time the study was in force, $94 \%$ of the children were being treated with ARV. The first prophylaxis for PJP was utilized for 121 children $(68 \%)$ and the second for 7 children (4\%). The use of monthly IVIG was prescribed for 47 patients $(26 \%)$. Five of the infected children died during the study period.

From the total of 291 medical files studied, 252 patients were followed in an ambulatory regime, receiving an average of 2.7 consultations every six months or 5.4 per year. The 43 children who frequented the day-hospital program, all of them infected, were seen almost every month, for an average of 10.6 consultations per year. For the 23 hospitalized children, the frequency of hospitalizations was 2.7 per patient per year. In general, and as expected, there was greatest care intensity among those patients seriously afflicted, followed by those classified as having a light/ moderate condition, and finally the exposed.

As expected, the different treatment modalities are followed by children with different levels of severity. Thus all exposed children (112) 
were attended in ambulatory service, none were attended by the day-hospital service, and only one of them was hospitalized. Of the 179 infected children followed during the study period, $78.21 \%$ were in ambulatory, $24.02 \%$ in hospitalday service, and $12.29 \%$ were hospitalized. Hospitalized children were mainly those seriously afflicted. Twenty-six children (14.5\% of total) were attended by more than one care mode, which made the mean total cost for a patient higher than it would have been if only followed-up by one modality.

\section{Unit costs of procedures}

The unit costs that were ascertained based on the cost system of the Instituto da Criança are presented in Table 1, disaggregated, in agreement with the existing system of costs at the hospital, by type of procedure (laboratory exams, imaging, medical procedures, and hospital daily rates). These costs, as was already mentioned, include all supplies and services consumed in their production (personnel, materials, medications, and indirect costs). It is important to emphasize the relatively high cost of an ambulatory consultation ( $\mathrm{R} \$ 217.25)$, if compared, for example, to staying a day in the infirmary (R\$ 434.57), principally arising from the significant consumption of medications (mainly ARV), which correspond to $43 \%$ of total ambulatory costs. These costs, as was already mentioned, include all supplies and services consumed in their production (personnel, materials, medications, and indirect costs).

\section{Mean costs of ambulatory care}

The mean cost of ambulatory care was very different for the two principal patient categories, being much higher for the infected than for the exposed (Tables 2 and 3).

\section{- Infected patients}

(severe and light/moderate)

The 140 infected patients generated 481 ambulatory consultations during the six month period, an average of 6.87 per patient/year (Table 2). Total cost per ambulatory consultation was that of $\mathrm{R} \$ 730.70$, and the cost of medication was $\mathrm{R} \$$ 277.91. Medication represented $52 \%$ of total cost, mainly because of ARV (60.4\%). Medical consultations were the second-most important item, at $18.8 \%$ of the total, followed by emergency room daily costs at $12.7 \%$. Laboratory exams and imaging diagnostics had little weight in the total $(3.7 \%$ and $2.7 \%$, respectively).
Among the ARV, the major contributors to cost were Ritonavir (39.8\%), Nelfinavir (15\%), Lamivudine (7.6\%), Zidovudine (7.5\%), Didanosine (7\%), and Indinavir (5.8\%).

Among the laboratory exams, the ones the contributed most to mean ambulatory costs were hematology (42.4\%) and immunology (30.2\%), followed by biochemistry and molecular biology. Among imaging diagnostics the costliest item was radiology $(56.6 \%)$, followed by tomography and ultrasound (22.4 and $13.6 \%$, respectively).

The cost of care was influenced by the severity of the case, with patients severely afflicted costing $30 \%$ more per consultation than those lightly/moderately afflicted (Table2).

\section{- Exposed patients}

There were 112 exposed patients attended at the ambulatory during the period of six months, resulting in 201 ambulatory consultations - an average of 3.59 per patient exposed/year. For these patients the total cost of each consultation was R \$ 258.62 without medication and R \$ 264.29 with medication (Table 2).The small difference between the two was due to the low consumption of ARV by these patients. These children only received the protocol component for prevention of vertical transmission after birth that consisted of Zidovudine (AZT) exclusively until six weeks of age. Another medication prescribed routinely during the course of the first year of life is Sulphametoxazol-trimetroprim, indicated for PJP. For these patients the cost of laboratory exams contributed a much larger share of the total cost $(12 \%)$ than that of those infected. It is worthwhile pointing out that the definition for HIV diagnosis is made through molecular biology exams (PCR RNA HIV-1), carried out on two or three occasions.

\section{Average cost per hospital-day service}

The patients served by the day-hospital were all infected, totaling 43 patients who received 229 services - a mean of 10.66 services per patient/ year. Among these patients, the total cost per service, not considering medication, was $\mathrm{R} \$ 154.40$, and the cost with medication was R 701.30 ( Table 2). Thus, as in the case of ambulatory treatment, the medications represented the greatest portion of total cost $(78 \%$, a greater percentage than in the ambulatory mode), corresponding to $57.8 \%$ for ARV, and $41.3 \%$ for other medications. However in the day-hospital modality the cost of medication was fundamentally due to the prescription of IVIG, an immunomodulator indicated for reducing repeated bacteriological 
Selected unitary costs per exam, consultation and other procedures at the Instituto da Criança, Hospital das Clínicas, Faculdade de Medicina, Universidade de São Paulo. São Paulo, Brazil, 2002.

\begin{tabular}{|c|c|c|c|c|c|c|c|}
\hline & $\begin{array}{c}\text { Personnel } \\
\text { (R\$) }\end{array}$ & $\begin{array}{l}\text { Materials } \\
\qquad(\mathrm{R} \$)\end{array}$ & $\begin{array}{l}\text { Medications } \\
\text { (R\$) }\end{array}$ & $\begin{array}{l}\text { Other } \\
\text { (R\$) }\end{array}$ & $\begin{array}{c}\text { Direct } \\
\text { cost (R\$) }\end{array}$ & $\begin{array}{l}\text { Indirect } \\
\text { cost (R\$) }\end{array}$ & $\begin{array}{c}\text { Total } \\
\text { cost }(\mathrm{R} \$)\end{array}$ \\
\hline Laboratory exams & - & - & - & - & - & - & - \\
\hline Hematology & 4.60 & 0.36 & - & 0.14 & 5.10 & 1.62 & 6.72 \\
\hline Biochemical & 0.72 & 0.54 & - & 0.03 & 1.29 & 0.34 & 1.63 \\
\hline Immunology & 2.89 & 8.30 & - & 0.16 & 11.35 & 0.96 & 12.31 \\
\hline Molecular biology & 1.98 & 0.05 & - & 0.83 & 2.87 & 2.76 & 5.63 \\
\hline Microbiology * & 1.21 & 0.99 & - & 0.08 & 2.28 & 0.54 & 2.82 \\
\hline Special exams * & 0.67 & 0.55 & - & 0.05 & 1.26 & 0.30 & 1.56 \\
\hline Diagnostic/Radiology & - & - & - & - & - & - & - \\
\hline Radiology & 36.13 & 1.73 & - & 2.20 & 40.06 & 14.01 & 54.07 \\
\hline Ultrasound & 18.47 & 0.30 & - & 3.89 & 22.65 & 11.17 & 33.82 \\
\hline Tomography & 92.23 & 11.94 & - & 8.53 & 112.70 & 39.47 & 152.17 \\
\hline Echocardiogram & 31.68 & 0.07 & - & 2.59 & 34.35 & 34.83 & 69.17 \\
\hline Electrocardiogram & - & 1.25 & - & 3.44 & 4.69 & 6.75 & 11.44 \\
\hline Other exams ** & 17.27 & 0.07 & - & 0.16 & 17.49 & 6.10 & 23.60 \\
\hline Procedures $* \star \star$ & - & - & - & - & - & - & - \\
\hline Consultations & 77.11 & 1.05 & 92.88 & 2.49 & 173.53 & 43.72 & 217.25 \\
\hline Emergency room consultations & 11.65 & 0.14 & 0.82 & 0.86 & 13.47 & 15.63 & 29.10 \\
\hline Ambulatory surgery & 140.93 & 0.34 & - & 1.46 & 142.72 & 27.31 & 170.04 \\
\hline Daily rates & - & - & - & - & - & - & - \\
\hline Infirmary & 134.20 & 17.43 & 74.21 & 10.54 & 236.39 & 138.18 & 434.57 \\
\hline Intensive care & 396.84 & 73.47 & 101.29 & 20.62 & 592.21 & 337.58 & 929.79 \\
\hline Day-hospital & 90.49 & 7.10 & 184.14 & 2.14 & 283.87 & 76.81 & 360.68 \\
\hline \multicolumn{8}{|l|}{ Emergency room } \\
\hline (patient under observation) & 237.92 & 39.60 & 0.02 & 3.03 & 280.56 & 204.28 & 484.85 \\
\hline
\end{tabular}

infections or for the control of immune-mediated plateletopenia (i.e. platelet depletion). The day-hospital consultations carried out represent $18 \%$ of the cost, the remainder being laboratory exams (2.4\%), imaging diagnostics (1.2\%), and emergency room charges $(0.3 \%)$. In this modality there was little difference between medical conditions of different severity, with the cost of the seriously ill being only slightly greater $(5.3 \%)$ than that of the lightly/moderately afflicted.

\section{Average cost for hospitalization}

Once again, the average cost for hospitalization was very different between infected and exposed patients, being 22 times greater for those infected (Table 2). Meanwhile, only one exposed patient was hospitalized.
There were 22 infected patients hospitalized, resulting in a total of 30 hospital stays in the six month period, or an average of 2.73 stays per patient/year. The total cost per hospital stay was $\mathrm{R} \$ 6,093.12$, not including medication, and $\mathrm{R} \$ 7,075.12$, including medication.

The structure of hospitalization costs has significantly different characteristics than those of ambulatory or day-hospital. The major cost item of hospitalization is the daily bed cost, at $81.8 \%$ of the total (infirmary at $71.9 \%$ the biggest component of this, followed by intensive care at 9.8\%). Imaging diagnostic exams represent a higher proportion $(2.9 \%)$, than laboratory exams (1.5\%).

Medications are responsible for only $13.8 \%$ of the total, much less than in the ambulatory and day-hospital modalities. Their composition 
Summary of treatment costs per service provided for ambulatory and hospitalized patients. Instituto da Criança, Hospital das Clínicas, Faculdade de Medicina, Universidade de São Paulo. São Paulo, Brazil, 2002.

\begin{tabular}{lccc}
\hline & $\begin{array}{c}\text { Number of patients } \\
\text { during the period }\end{array}$ & Cost/Service (R\$) & Medications (\%) \\
& 252 & - & 61.96 \\
Ambulatory & 140 & 730.70 & 64.59 \\
Infected & 77 & 800.09 & 57.04 \\
Severe condition & 63 & 615.81 & 2.15 \\
Ligh/Moderate condition & 112 & 264.29 & - \\
Exposed & 43 & - & 77.98 \\
Day-hospital & 43 & 701.30 & 78.40 \\
Infected & 31 & 710.83 & 76.78 \\
Severe condition & 12 & 674.95 & - \\
Light/Moderate condition & 0 & - & - \\
Exposed & 23 & - & 13.88 \\
Hospitalized & 22 & $7,075.12$ & 11.35 \\
Infected & 19 & $7,623.40$ & 30.82 \\
Severe condition & 3 & $4,960.56$ & 3.55 \\
Ligh/Moderate condition & 1 & 435.52 & \\
Exposed & & & \\
\hline
\end{tabular}

is also different, with antibiotics predominating (51\%), followed by other medications (24.5\%), and ARV (21.5\%). Calculating an average stay of 15.23 days per hospitalization (14.10 days in the infirmary, 0.83 in the intensive care unit, and 0.30 in the emergency room), the resulting average cost per patient/day was R $\$ 464.14$.

The seriousness of the medical condition clearly influenced the cost of hospitalization: the cost per hospitalization for lightly/moderately afflicted patients was $42.9 \%$ of the cost for seriously afflicted ones, if medications were not taken into consideration. Meanwhile, the cost of medications revealed itself as being significantly higher for lightly/moderately afflicted patients: $\mathrm{R} \$ 1,528.62$ versus $\mathrm{R} \$ 865.08$ for those gravely afflicted. However, only one of the lightly/moderately afflicted patients consumed $\mathrm{R} \$ 1,092.00$ worth of one extremely expensive medication, Cefepima. In relationship to the small number of patients in this category, this patient distorted the value and composition of cost, with the weight of medication being much higher (30.8\%), and the daily rates less (66\%). The other items (laboratory and imaging) continued to have little weight.

Figure 1 illustrates the above results, and shows that hospitalization treatment cost level and composition vary greatly according to the patient category, but the greatest cost component is always hospital daily rates. This is very different from the cost of ambulatory and hos- pital-day, as has already been shown, where the main cost factor is medications, principally from ARV and IVIG.

\section{Cost structure per type of input}

Cost structure per type of input varied greatly depending on the treatment modality and medical condition of the patient. Considering only infected patients in ambulatory care, personnel costs represented $21.5 \%$ of the total-versus $62 \%$ for medications, and $13.6 \%$ in indirect prorated costs. There was no great difference between gravely and lightly/moderately afflicted patients.

In the day-hospital modality the same categories of inputs stood out: medications (78\%), personnel (13.2\% of total cost), and indirect prorated costs $(7.4 \%)$, while other costs and materials contributed only $1.4 \%$ to the total.

For hospitalization the cost structure was quite different, with indirect costs representing the greatest total cost component (44.7\%), more than personnel costs $(34.1 \%)$, and medications (13.8\%). This composition was distinguished by the importance of the hospital infrastructure necessary for caring for hospitalized patients.

\section{Annual costs of treatment}

Table 3 presents the total annual treatment costs per patient, selected for each modality of care 
1a) Ambulatory

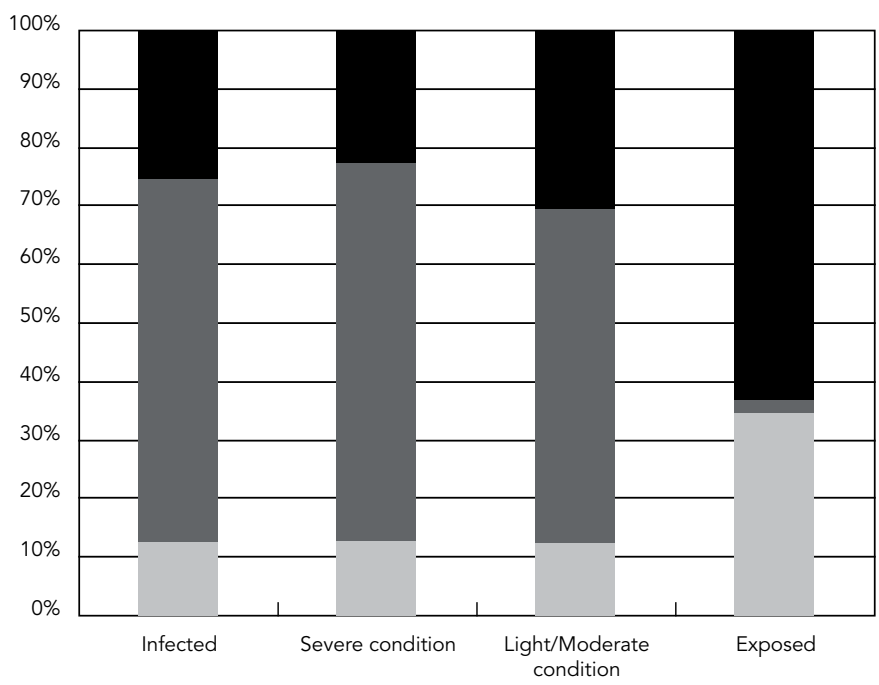

aboratory exams/Imaging/

Other procedures

Medicines

Stay (daily basis)

\section{1b) Hospitalized}

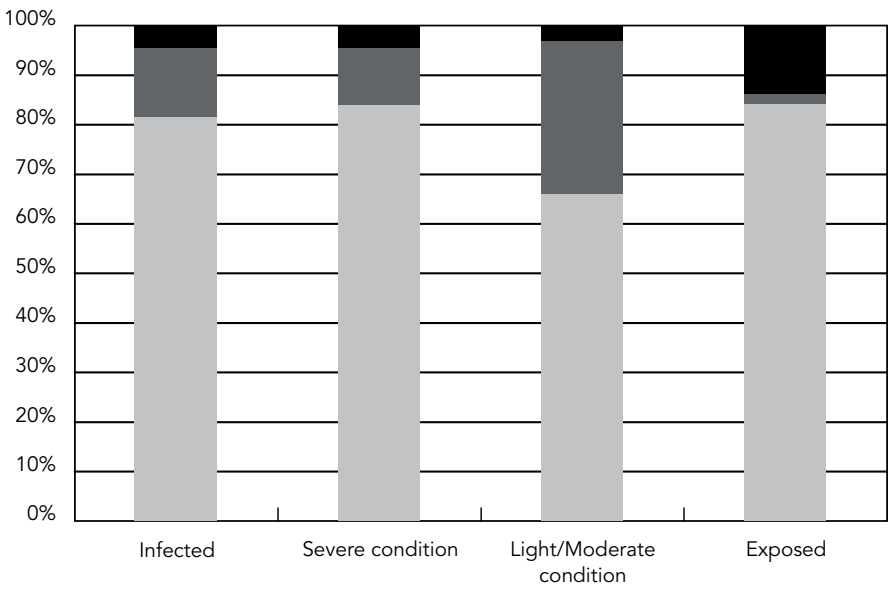

Laboratory exams/Imaging/

Other procedures

Medicines

Stay (daily basis)

(ambulatory, day-hospital, and hospitalization) and for each patient category (seriously ill, lightly/moderately afflicted, and exposed). It makes clear that the annual treatment cost is greater in the case of hospitalization, because, on average, it treats more seriously afflicted patients, who require a more ample and expensive set of resources. On the other hand, for exposed patients, the hospitalization cost is a little different, and lower than the cost of an ambulatory regime. It must be emphasized that the costs shown are averages, and actually mask the significant variance between individual cases.

The seriousness of a medical condition significantly influenced the cost of treatment of the patients, mainly in the case of ambulatory: the annual cost of the seriously afflicted patients in this modality was $63 \%$ greater than that of the lightly/ 
Annual costs related to children exposed or infected by HIV. Instituto da Criança, Hospital das Clínicas, Faculdade de Medicina, Universidade de São Paulo. São Paulo, Brazil, 2002.

\begin{tabular}{lccc}
\hline & $\begin{array}{c}\text { Number of patients } \\
\text { during the period }\end{array}$ & Services/Year & $\begin{array}{c}\text { Annual cost per } \\
\text { category (R\$) }\end{array}$ \\
\hline Ambulatory & 252 & 5.41 & - \\
Infected & 140 & 6.87 & $5,021.16$ \\
Severe condition & 77 & 7.56 & $6,047.28$ \\
Light/Moderate conditions & 63 & 6.03 & $3,714.45$ \\
Exposed & 112 & 3.59 & 948.63 \\
Day-hospital & 43 & 10,65 & - \\
Infected & 43 & 10.65 & $7,469.63$ \\
Severe conditions & 31 & 10.84 & $7,704.74$ \\
Light/Moderate conditions & 12 & 10.17 & $6,862.26$ \\
Exposed & 0 & - & - \\
Hospitalized & 23 & 2.70 & - \\
Infected & 22 & 2.73 & $19,295.80$ \\
Severe conditions & 19 & 2.63 & $19,353.34$ \\
Light/Moderate conditions & 3 & 3.33 & $18,823.16$ \\
Exposed & 1 & 2.00 & 871.03 \\
\hline
\end{tabular}

moderately afflicted ones. This was because the seriously afflicted had more consultations per year (7.6 versus 6.0 ), and a $30 \%$ higher cost per consultation ( $\mathrm{R} \$ 800.09$ versus $\mathrm{R} \$ 615.81$ ).

The total cost for a child being followed at the Instituto da Criança, considering the diverse services and modes of frequency, is shown in Figure 2. The data show the importance of the child's serological status as a determinant of cost, as the average annual cost for children infected with HIV (R\$ 8,092.71) is eight times that of those that have been exposed ( $\mathrm{R} \$ 956.41)$.

\section{Discussion}

According to the estimates of this study, whose scope is limited to only a single hospital institution, the annual cost of HIV-infected children is high, corresponding to $106 \%$ of the GDP (Gross Domestic Product) per capita of the country for the year 2002 13, and almost thirty times the annual amount spent per capita on SUS ( $R \$ 8,092.71$ or US\$ 3,312.61 against $\mathrm{R} \$ 271.00$, in 2002, taking in consideration the 2002 exchange rate). However, this high cost does not take into consideration that the economic and social costs of HIV/AIDS are also relevant, which makes the treatment cost-effective (see, for instance, Couttolenc BF, Waldvogel B, Santos NJS, Pluciennik AMA, Aveiro MIG, Marques HHS, et al. Analysis of Cost and Impact of Antiretroviral Therapy, a tech- nical report presented to the Brazilian National STD/AIDS Program; 2004).

On the other hand, any discussion about the cost or the cost-benefit relationship of HIV/AIDS treatment requires estimates consistent with the real costs. Therefore the present study represents an important advance for Brazil, as it is the first one to focus on children living with HIV/AIDS.

The main studies that estimate the costs of treating children with HIV/AIDS have been carried out in developed countries, and present, in general, a small number of patients 7,9. Only Hsia et al. ${ }^{8}$ evaluated a series of more than 100 patients, obtaining the data through interviews. In studies with adults, larger samples are analyzed, through interviews 14,15 , or reviews of medical records 9,16,17, aside from other approaches. Some of these methodologies are impossible to replicate in many healthcare services and institutions in Brazil, due to the absence of comprehensive data on costs, or even data on expenditures. Among the more recent publications, Schackman et al. 18 , estimated US $\$ 15,917.00$ to be the annual average cost for treatment of an infected adult utilizing ARV in the United States, of which $76 \%$ was for ARV and $13 \%$ for the cost of hospitalization. Roberts et al. 19, also in the United States, estimated US\$20,114.00 as the annual cost, of which $46 \%$ was for medication and $31 \%$ for hospitalization. Studying only children infected through their mothers, Sansom et al. ${ }^{20}$ gave 


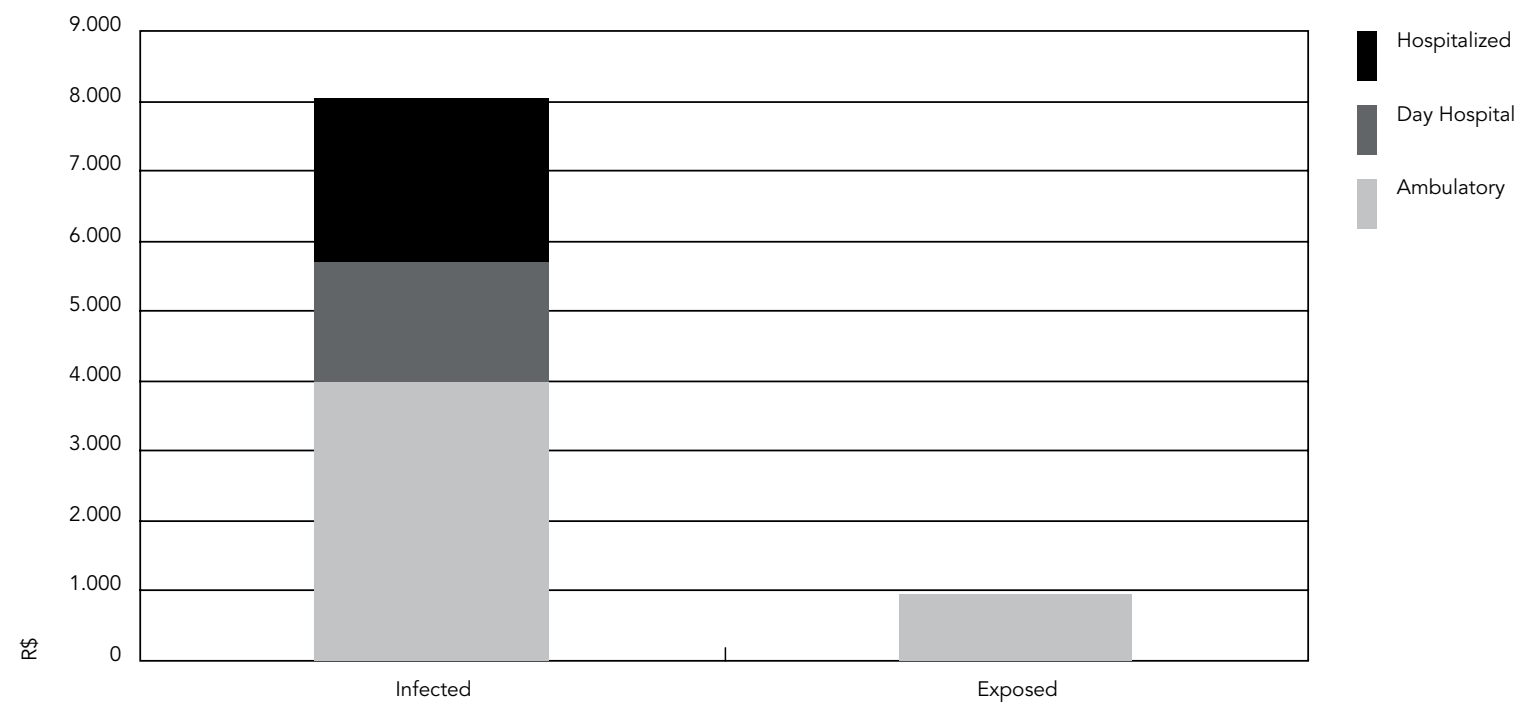

US $\$ 12,114.00$ as the estimate for annual treatment costs (medication, hospitalizations, and laboratory exams), of which $75 \%$ was for ARV drugs and $17 \%$ for hospitalization.

In Brazil, the first study of treatment costs for patients with HIV/AIDS was carried out in 1992 by Médici \& Beltrão ${ }^{4}$, and estimated the cost of hospital treatment in three hospitals, using data from 1991. The annual cost estimated was US\$ $16,689.00$ per patient (with a mean of 1.26 hospitalizations per year and 23.6 day of hospitalization per year) and the mean cost per hospitalization was US\$13,245.00.

An important study of treatment costs for cases of HIV infection in adults in our context was done by a team from the Fundação Instituto de Pesquisas Econômicas (FIPE; Economic Research Institute Foundation) 5, and evaluated 1996 costs for the following care modalities: conventional hospitalization, day-hospital, ambulatory, and home-care. Various healthcare providers were studied, all of them in the State of São Paulo. The direct costs were estimated, starting with an analysis of medical records $(n=2,281)$ and the indirect ones starting with a percentage calculated for one of the treatment centers (Center for Reference and Training for STD/AIDS). The total mean cost per year (1996) was $\mathrm{R} \$ 6,121.42$ (US\$ 5,597.49, using the 1996 exchange rate) 5 . The cost per hospitalization was $\mathrm{R} \$ 5.438,40$ and the annual cost for ambulatory treatment was $\mathrm{R} \$ 4,863.33$.

A third, more recent, study, carried out by PLANISA (Planejamento e Organização de Institutos de Saúde/Planning and Organization of Health Institutes) for REFORSUS (Reforço à Reorganização do Sistema Único de Saúde, Ministério da Saúde/Reinforcement for the Reorganization of the Unified National Health System) 6 , had the objective of analyzing the cost of carrying out 107 procedures in 25 hospitals, totaling around 15,000 patients. The costs for treating patients with HIV/AIDS were estimated in a sample of 183 patients, the majority of them adults, from ten hospitals. The methodology employed also followed the same general principles applied in the present study. However, some important details deserve mention. First of all, unlike the present study, the PLANISA study did not estimate the cost of outsourced procedures and/or did not show the all the real costs to the hospital (such as the medications distributed by the Ministry of Health). The PLANISA study found an average cost of R \$3,933.70 per hospitalization, of which $60.9 \%$ consisted of hospital services (daily costs, room rates, etc.), $11.5 \%$ professional services (doctor's fees), $9.9 \%$ diagnostic services, and 13\% materials and medications.

After converting to the same base (average 2002 Real and US dollars for the first half of 2002, 
for a rate of US\$1.00 $=\mathrm{R} \$ 2.443$ ), to permit the comparison of studies carried out during different time periods 5,6, the estimated costs of the present study and the other studies appear consistent. Various factors contributed to the differences observed between the studies. Firstly, the fact that all the studies, with the exception of this one, were done with mostly adult patients. Secondly, the mean hospitalization stay varied, from 23.6 days/year in the Médici \& Beltrão 4 study, to 16.7, in the FIPE study 5 , and 16.1, in the PLANISA study 6 , versus 15.2, in the present study. Thirdly, it is necessary to point out that there has been a reduction in the cost of ARV since its introduction, which results in lower costs in more recent studies. Finally, the proportion of HIV-positive but not ill patients varied in the different studies and the costs for the various categories were not calculated separately in most studies.

Despite the differences in methodologies and samples, the costs estimated by the Instituto da Criança are comparable to the other studies. The cost for hospitalization and for ambulatory service was demonstrated to be around $40 \%$ higher, but this difference is consistent with the evidence in available literature that in general the costs for treating children have a tendency to be higher than those for adults 8 . Aside from this, this study was carried out in a university hospital, which normally has higher costs than an institution that does not have teaching and research activities. On the other hand, the estimated costs here were substantially lower than those found in studies carried out in developed countries, a fact also stated by the abovementioned report by Couttolenc et al.

Because the present study is limited to one institution, with the characteristics of a university hospital, the costs estimated by the Instituto da Criança should not be seen as representative of the different treatment centers in the country. As previously mentioned, the costs were comparable to those obtained in previous studies, and the composition also was consistent with that of the others. In addition, since 1994 the Brazilian National STD/AIDS Program has elaborated treatment guidelines for HIV/AIDS infected children. Thus the medications utilized, the consultations and procedures necessary for caring for this population should be common to other pediatric services, demonstrating the usefulness of the data presented in this study.

Aside from the question of being representative of the population studied, there are a few other difficulties and limitations to be mentioned. First of all, it was necessary to develop a specific methodology to estimate the treatment cost of a specific disease, as the cost verification system adopted by the Instituto da Criança - similarly to the majority of Brazilian hospitals - did not permit estimating costs by procedure or by patient. On the other hand, difficulty in utilizing medical records as a data source was experienced, as they are not standardized and present numerous gaps and impreciseness in treatment recording. This meant that extensive time was spent collecting data.

The study was, by its very nature, complex and multidisciplinary, requiring the collaboration of various professionals from different disciplines, allying medical expertise in the treatment of HIV/AIDS patients, with economic-administrative expertise in cost estimation.

This study offers, aside from verifying the cost of caring for children infected and exposed to HIV in its various modalities, the development of instruments for obtaining data that permit the verification of these costs in institutions that already possess a cost control system. The necessity for the institutions to perfect and implement such systems must be emphasized, in order to contribute to bettering the organization and effectiveness of health services offered to the community.

In conclusion, the study gave evidence of three principal factors that influence treatment costs for children: (i) the treatment modality (ambulatory, day-hospital, or hospitalization), with hospitalization requiring a set of inputs and services different from ambulatory and hospital day; (ii) the severity of the medical condition, with patients seriously afflicted having a significantly greater cost than those lightly/moderately afflicted or exposed; (iii) associated with theses factors, the consumption of medications, especially antiretrovirals, corresponds to the greatest part of costs in ambulatory and day-hospital.

In regard to the medications, their weight on total costs suggests: (i) the systematic adoption and application of treatment protocols that, aside from being effective from a clinical point of view, also take into consideration the cost of medications and; (ii) the strengthening of price negotiating power with the manufacturers of the medications and the improvement of controls of storage, distribution, and consumption, contributing to the sustainability of the program of universal free distribution to all those infected or exposed to HIV and; (iii) give priority to stimulating patients' treatment adherence, thus avoiding the appearance of resistant strains of HIV and the necessity for introducing new drugs. When hospitalization becomes necessary: (i) the tendency in recent years of limiting hospitalization to only those cases that really require these technological resources should be reinforced; (ii) sys- 
tematically search out and eliminate waste and inefficiencies that unnecessarily contribute to high costs and; (iii) find more adequate and less expensive alternatives for the numerous "social cases", patients that do not require hospitalization but remain hospitalized because of lack of family or adequate living conditions.

\section{Resumo}

O objetivo deste estudo foi estimar e analisar os custos de tratamento da criança com HIVIAIDS em um hospital universitário de São Paulo, Brasil. Foram analisados 291 prontuários de crianças expostas ou infectadas acompanhadas no Instituto da Criança, Hospital das Clínicas, Faculdade de Medicina, Universidade de São Paulo, em março de 2002. O custo foi estimado por categoria de paciente (exposta e infectada) e nível de gravidade (graves e leves/moderados), com base na quantidade de procedimentos e insumos utilizados no tratamento, e valorizado monetariamente por meio do sistema de apuração de custos existente no Instituto da Criança. O custo total estimado de tratamento da criança exposta ao HIV foi de $R \$$ 956,41 e da criança infectada de $R \$ 8.092,71$ por ano. O custo do tratamento ambulatorial foi de $R \$ 6.047,28, R \$ 3.714,45 e$ $R \$ 948,63$, respectivamente para os pacientes infectados graves, leves/moderados e para as crianças expostas, e o custo médio de internação foi de $R \$ 19.353,34$, $R \$ 18.823,16$ e $R \$ 871,03$, respectivamente. O custo foi fortemente influenciado pelo consumo de medicamentos e comparável aos obtidos pelos demais estudos publicados, embora inferior ao estimado em estudos internacionais.

HIV; Síndrome de Imunodeficiência Adquirida; Custos de Cuidados de Saúde; Cuidado da Criança

\section{Contributors}

The authors actively participated in all phases of the study: H. H. S. Marques in the review of the literature, study design, creation and perfection of instruments, discussion of results, and the final writing and editing of the article; M. R. D. O. Latorre in the study design, field work and supervision, data bank elaboration, spreadsheets and data entry, writing and editing the article; B. F. Couttolenc in the review of literature and study design, coordination of verifying costs and elaboration of cost spreadsheets, economic analysis, results discussion, writing and editing the article; M. Z. Aquino study design, budget elaboration, editing the proposal, elaboration of instruments, checking costs, field supervision, discussion of results and revision of article; M. I. G. Aveiro review of literature, elaboration of instruments, cost verification, coordination of cost centers at the Instituto da Criança, Hospital das Clínicas, Faculdade de Medicina, Universidade de São Paulo and evaluation of cost gaps, discussion of results and revision of article; A. M. A. Pluciennik review of literature, study design, budget elaboration, proposal revision, cost verification, results discussion, and article revision. 


\section{References}

1. Programa Nacional DST e AIDS. Guia de tratamento clínico da infecção pelo HIV em crianças. Brasília: Ministério da Saúde; 2004.

2. Coordenação Nacional de DST/AIDS. Terapia anti-retroviral e saúde pública: um balanço da experiência brasileira. Brasília: Ministério da Saúde; 1999.

3. Teixeira P, Vitoria M, Barreira D, Dhalia C, Castilho EA. AIDS epidemic in Brazil: present situation, national response and future trends. Actualizaciones en Sida 2001; 9 Suppl 1:25-33.

4. Médici AC, Beltrão KI. Custos da atenção médica à AIDS no Brasil: alguns resultados preliminares. Rio de Janeiro: Escola Nacional de Ciências Estatísticas/Instituto Brasileiro de Geografia e Estatística; 1992. (Relatórios Técnicos ENCE/IBGE, 01/92).

5. Fundação Instituto de Pesquisas Econômicas. Estimativa dos custos dos tratamentos da AIDS no Brasil - 1996. São Paulo: Fundação Instituto de Pesquisas Econômicas; 1998.

6. Matos AJ. Apuração dos custos de procedimentos hospitalares: alta e média complexidade. São Paulo: Planejamento e Organização de Instituições de Saúde; 2002.

7. Hegarty JD, Abrams EJ, Hutchinson VE, Nicholas SW, Suarez MS, Hegarty MC. The medical care costs of human immunodeficiency virus-infected children in Harlem. JAMA 1988; 260:1901-5.

8. Hsia DC, Fleishman JA, East JA, Hellinger FJ. Pediatric human immunodeficiency virus infection. Recent evidence on the utilization and costs of health services. Arch Pediatr Adolesc Med 1995; 149:489-96.

9. Havens PL, Cuene BE, Holtgrave DR. Lifetime cost of care for children with human immunodeficiency virus infection. Pediatr Infect Dis J 1997; 16: 607-10.

10. Matos AJ. Gestão de custos hospitalares: técnicas, análise e tomada de decisão. São Paulo: Editora STS; 2002.
11. Associação Médica Brasileira. Classificação brasileira hierarquizada de procedimentos médicos. São Paulo: Associação Médica Brasileira; 2005.

12. Centers for Disease Control and Prevention. 1994 revised classification system of human immunodeficiency virus infection in children less than 13 years. MMWR Morb Mortal Wkly Rep 1994; 43: $1-10$.

13. Instituto Brasileiro de Geografia e Estatística/Instituto de Pesquisa Econômica Aplicada. Sistema de contas nacionais. http://www.ipeadata.gov.br/ ipeaweb.dll/ipeadata?65370046 (accessed on 14/ Mar/2007).

14. Hellinger FJ. The lifetime cost of treating a person with HIV. JAMA 1993; 270:474-8.

15. Bozzette AS, Joyce G, McCaffrey DF, Leibowitz AA, Morton SC, Berry SH, et al. Expenditures for the care of HIV-infected patients in the era of highly active antiretroviral therapy. N Engl J Med 2001; 344: 817-23.

16. Weiss PJ, Kennedy CA, Wallace MR, Nguyen MT, Oldfield 3rd EC. Medication costs associated with the care of HIV-infected patients. Clin Ther 1993; 15:912-6.

17. Beck EJ, Miners AH, Tolley K. The cost of HIV treatment and care: a global review. Pharmacoeconomics 2001; 19:13-39.

18. Schackman BR, Gebo KA, Walensky RP, Losina E, Muccio T, Sax PE, et al. The lifetime cost of current human immunodeficiency virus care in the United States. Med Care 2006; 44:990-7.

19. Roberts RR, Kampe LM, Hammerman M, Scott RD, Soto T, Ciavarella GG, et al. The cost of care for patients with HIV from the provider economic perspective. AIDS Patient Care STDS 2006; 20:876-86.

20. Sansom SL, Anderson JE, Farnham PC, Dominguez K, Soorapanth S, Clark J, et al. Updated estimates of healthcare utilization and costs among perinatally HIV-infected children. J Acquir Immune Defic Syndr 2006; 41:521-6.

Submitted on 15/May/2006

Final version resubmitted on 20/Mar/2007

Approved on 04/Apr/2007 